\title{
Perfluorocarbons and their use in Cooling Systems for Semiconductor Particle Detectors
}

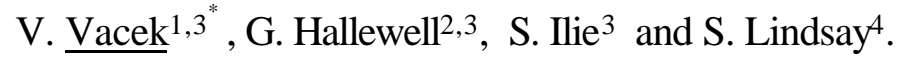 \\ ${ }^{1}$ Czech Technical University, Prague, Czech Republic; \\ ${ }^{2}$ Centre de Physique des Particules de Marseille, France; \\ ${ }^{3}$ CERN, 1211Geneva 23, Switzerland \\ ${ }^{4}$ Department of Physics, University of Melbourne, Australia
}

\begin{abstract}
We report on the development of evaporative fluorocarbon cooling for the semiconductor pixel and micro-strip sensors of inner tracking detector of the ATLAS experiment at the future CERN Large Hadron Collider (LHC). We proceeded with studies using perfluoro-n-propane (3M-"PFG $\left.{ }_{3} \mathrm{~F}_{8}\right)$, perfluoro-n-butane (3M-"PFG 5040"; $\left.\mathrm{C}_{4} \mathrm{~F}_{10}\right)$, trifluoro-iodo-methane $\left(\mathrm{CF}_{3} \mathrm{I}\right)$ and custom $\mathrm{C}_{3} \mathrm{~F}_{8} / \mathrm{C}_{4} \mathrm{~F}_{10}$ mixtures. Certain thermo-physical properties had to be verified for these fluids. Sound velocity was calculated for the pure fluids and custom mixtures. A Sonar instrument was developed for the measurement of sound velocity in the above fluids at a variety of temperatures and pressures. Irradiation studies were made on the fluids using neutrons and gamma rays to determine their suitability for use in the high radiation environment at LHC.
\end{abstract}

Keywords: Data, experimental method, velocity of sound, alternative refrigerants, perfluorocarbons, mixtures.

\section{Introduction}

The silicon substrates of the silicon pixel and micro-strip sensors of the ATLAS inner tracker [1, 2] must be continuously operated at a temperature below $-7^{\circ} \mathrm{C}$ for a $\sim 10$ year operational lifetime at LHC. In addition, for physics motivations, the detector cooling system must present the minimum possible extra material. We have therefore investigated evaporative cooling with the fluorinated hydrocarbons of Table 1 . These combine high heat transfer coefficients with very low circulating coolant mass (1-2 $\mathrm{g} \mathrm{s}^{-1} / 100 \mathrm{~W}$ to evacuate). Liquid refrigerant can be delivered to the detector in capillaries with IDs as small as $0.6 \mathrm{~mm}$ or via ruby injectors. Other attractive features of fluorocarbon fluids in our application include high dielectric constant, non-flammability and high expected radiation resistance. The high radiation environment does, however, constrain the cooling circuits to operate in an oil-free mode this makes their design rather difficult.

\footnotetext{
* Corresponding Author
} 
The pixel and micro-strip detectors are divided into around 320 linear and disk-like arrays of silicon sensor tiles. The linear arrays ("ladders") have lengths varying between 80 and $160 \mathrm{~cm}$ with up to 13 sensors tiled along them. Individual sensors dissipate a maximum of $\sim 10 \mathrm{Watts}$, and cooling measurements were made up to the full projected power with heat transfer to the evaporative coolant through an area ranging between 3.5 and $12 \mathrm{~cm}^{2}$. The total dissipation of the ATLAS semiconductor tracking detectors will be around $60 \mathrm{~kW}$, and the final cooling system will comprise around 400 parallel evaporative channels with individual control of flow rate and evaporating temperature, supplied from a central compressor station.

Latent heat data for the various refrigerants are shown in Table 1, together with their saturated vapor pressures and the volume $\left(\mathrm{cm}^{3}\right)$ of vapor produced per $\mathrm{cm}^{3}$ liquid evaporated at $-15^{\circ} \mathrm{C}(\mathrm{a}$ temperature chosen to accommodate probable thermal impedances between the silicon substrates and the coolant). A target evaporation pressure of $1 \mathrm{bar}_{\text {abs }}$ would allow the use of very low-mass tube ( $\sim 0.2 \mathrm{~mm}$ wall aluminum or composite) in a variety of aspect ratios.

Table 1

Selected Refrigerant Properties $\left(-15^{\circ} \mathrm{C}\right)$

\begin{tabular}{|l|c|c|c|}
\hline \multirow{2}{*}{ Fluid formula } & Latentheat & Liquid-Gas Expansion & S.V.P. at - $15^{\circ} \mathrm{C}$ \\
\cline { 4 - 4 } & {$\left[\mathrm{kJ} \mathrm{kg}^{\prime}\right]$} & Factor & {$\left[\mathrm{bar}_{\text {abs }}\right]$} \\
\hline $\mathrm{C}_{3} \mathrm{~F}_{8}$ & 97 & 71.4 & 2.46 \\
\hline $\mathrm{C}_{4} \mathrm{~F}_{10}$ & 101.1 & 242.6 & 0.58 \\
\hline $\mathrm{CF}_{3} \mathrm{l}$ & 100.8 & 176.3 & 1.33 \\
\hline $\mathrm{C}_{3} \mathrm{~F}_{8} \mathrm{C}_{4} \mathrm{~F}_{10}$ & & & \\
$(50 / 50$, molar $)$ & 98.3 & 147.6 & $1.01 \mathrm{P}_{\mathrm{SV}}-1.65 \mathrm{P}_{\mathrm{SL}}$ \\
\hline
\end{tabular}

For the design of an effective cooling system [3], most of the engineering design parameters had to be studied. Presented results from the studies include:

- verification of fluid behavior reflecting predictions of the thermodynamic and transport properties of fluids $[4,5,6]$ - the cooling circuit of Fig. 1 was used for this purpose and several pilot detector structures were tested;

- velocity of sound measurements at low pressures [up to 4 bar $_{\text {abs }}$ ], performed mainly to verify the thermodynamic property predictions for the fluids, and to determine the composition of custom binary mixtures;

- heat transfer coefficient measurements during evaporation [6] for various heat fluxes (powers) and different fluids and mixtures;

- effects of neutron and gamma ray irradiation upon the fluids of interest. 


\section{Measurement Apparatus}

\subsection{The Evaporative Recirculator}

A closed-loop evaporative recirculator (Fig. 1) has been built for testing thermo-structures using all the fluids of Table 1. Structures are placed in a chamber purged with an inert gas $\left(\mathrm{N}_{2}\right)$ and maintained at $-7^{\circ} \mathrm{C}$, to simulate the environment of the silicon sensors in ATLAS.

The present circulator contains two compressor stages and a water-cooled condenser, also serving as a high-pressure liquid refrigerant reservoir. The first stage compressor ${ }^{1}$ is used only with low input pressure vapors as in the case of $\mathrm{C}_{4} \mathrm{~F}_{10}, \mathrm{CF}_{3} \mathrm{I}$ or $\mathrm{C}_{3} \mathrm{~F}_{8} / \mathrm{C}_{4} \mathrm{~F}_{10}$, since the pumping speed of the second stage compressor ${ }^{2}$ is insufficient at input pressures below 1 bar $_{\text {abs. }}$ This complexity was required to test four thermodynamically different fluids. These compressors will soon be replaced with a single stage dry scroll compressor ${ }^{3}$, with a measured pumping speed of $\sim 20 \mathrm{~m}^{3} \mathrm{hr}^{-1}$ for both $\mathrm{C}_{4} \mathrm{~F}_{10}\left(\mathrm{P}_{\text {in }}=0.25, \mathrm{P}_{\text {out }}=4\right.$ bar $\left._{\text {abs }}\right)$ and $\mathrm{C}_{3} \mathrm{~F}_{8}\left(\mathrm{P}_{\text {in }}=1.4, \mathrm{P}_{\text {out }}=8\right.$ bar $\left._{\text {abs }}\right)$.

Liquid refrigerant enters a four-channel supply manifold, whose pressure - defined by a regulator determines the liquid mass flow. Fluid enters the test structures via capillaries with diameters varying between 0.6 and $1 \mathrm{~mm}$, or via injectors made from synthetic ruby watch bearings with orifices varying between 210 and $300 \mu \mathrm{m}$. The temperature of evaporation of fluid in the test structures depends on the pressure in a 4-channel vapor collection manifold tank, controlled via feedback from a pressure sensor ${ }^{4}$ to a variable orifice valve located between the tank and the compressor input. The circulating mass flow is metered after the tank.

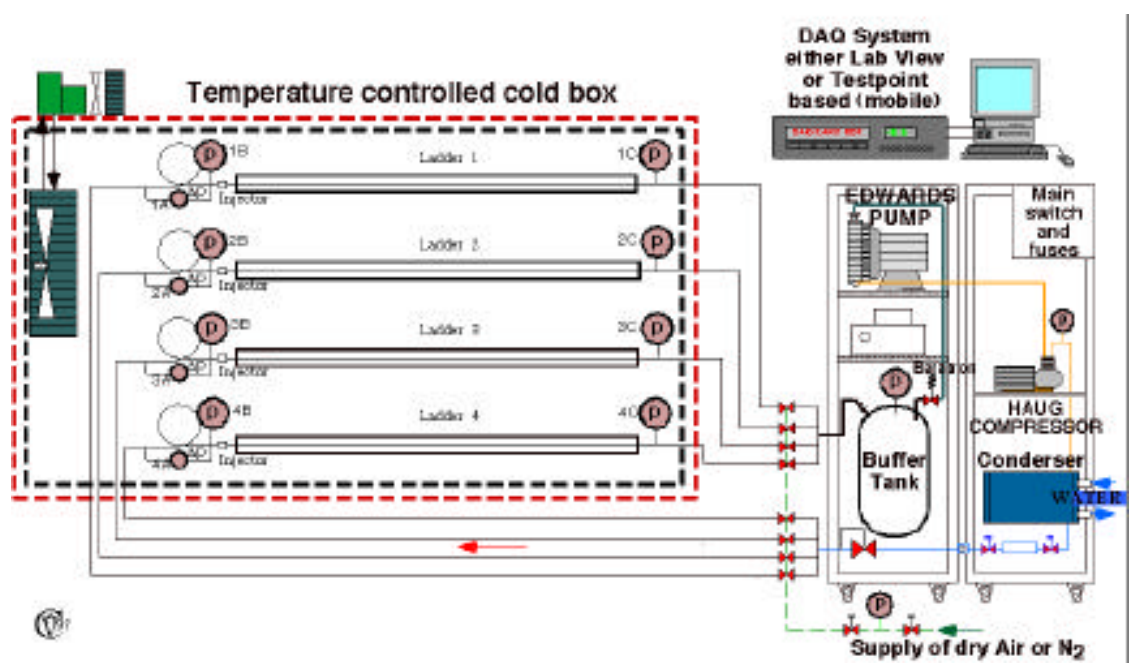

Fig. 1. The Two-Stage Evaporative Recirculator

\footnotetext{
${ }^{1}$ Edwards ECP 30 Dry Rotary Scroll Vacuum pump (rated $30 \mathrm{~m}^{3} \mathrm{hr}^{-1}$ air; $\mathrm{P}_{\text {in }} 1$ bar $_{\text {abs }}, \mathrm{P}_{\text {out }}=1.5$ bar $_{\text {abs }}$ limit)

${ }^{2}$ Haug SOGX 50-D4 Dry Piston Compressor (rated $3.6 \mathrm{~m}^{3} \mathrm{hr}^{-1}$ air, $\mathrm{P}_{\text {in }} 1$ bar $_{\mathrm{abs}} ; \mathrm{P}_{\text {out }}=9$ bar $_{\mathrm{abs}}$ limit)

${ }^{3}$ Atlas Copco Type SF4-8-120

${ }^{4}$ MKS Baratron Model 122B Range 0-5000 Torr ${ }_{a b s}$
} 


\subsection{The Sonar Gas Analyzer}

There were two main reasons for preparing the sonar gas analyzer:

- to verify available thermodynamic data for fluids of interest;

- to make a fast purity check of delivered fluids, and for possible verification of mixture compositions.

The sonar gas analyzer is shown in Fig. 2a. An aluminum tube contains a pair of ultrasonic transducers ${ }^{5}$ having a peak response at $45 \mathrm{kHz}$, and a separation of $944.5 \pm 1.0 \mathrm{~mm}$. The tube is surrounded by a coiled copper tube through which coolant was circulated over a temperature range from $-20^{\circ}$ to $40^{\circ} \mathrm{C}$. The temperature of the vapor within the tube was sampled to a precision \pm 0.1 ${ }^{\circ} \mathrm{C}$ by of pair of calibrated PT100 sensors. Pressure was monitored to \pm 1 torr by an electronic pressure gauge ${ }^{6}$.

The timing sequence is shown in Fig 2b., and is based on an earlier development [7]. Packets of eight $45 \mathrm{kHz}$ sound cycles are generated and transmitted through the vapor in the tube. Synchronous with the leading edge of the first cycle (A), a fast (4 MHz) transit time clock is started. This clock is stopped when an above-threshold sound signal is received (B), and the number of counted pulses is used together with the path length to calculate the sound velocity.

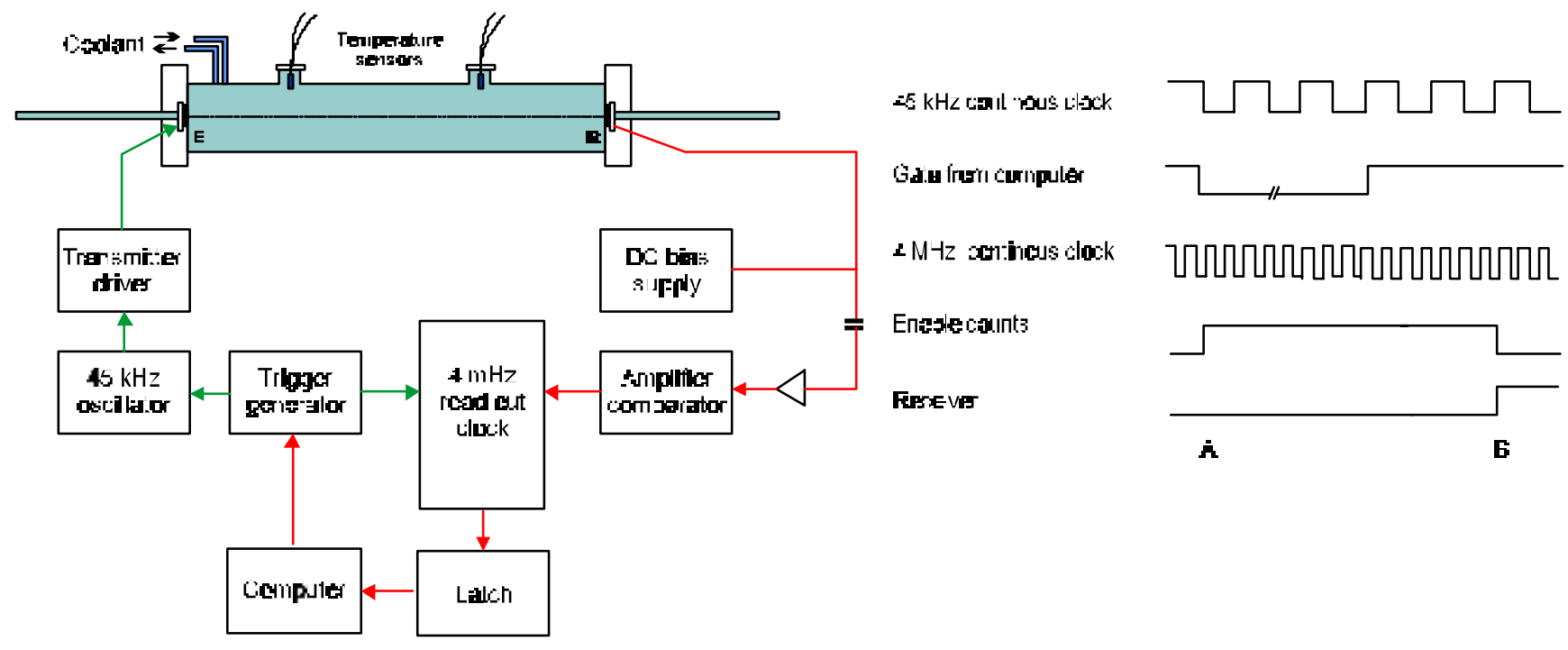

2a. View of the sonar gas analyzer.

2b. Timing Sequence of the sonar

Fig. 2. Schematics of the Sonar analyzer

\footnotetext{
${ }^{5}$ Polaroid Corp. Instrument grade transducer, part no 604142

${ }^{6}$ MKS Corp. "Baratron" Model 122B read by MKS Corp. Model 600 Pressure Controller.
} 


\subsection{Apparatus for Heat Transfer Coefficient (HTC) Measurements}

A second small, dry refrigeration circuit was constructed to allow simultaneous measurements of heat transfer coefficient (HTC) while full size thermo-structure prototypes were measured in the main circulator. Heat transfer coefficients were measured on a simplified "ladder" having 12 copper blocks soft-soldered onto a $1.6 \mathrm{~m}$ long cupro-nickel tube with $3.6 \mathrm{~mm}$ ID. On each block were a ceramic heater and a PT100 sensor. PT100's were fitted to the coolant tube in 13 positions between the blocks and at each end. Another sensor measured the liquid temperature upstream of the capillary or injector. In this tube, HTCs were deduced at 12 points along the tube from the (block-tube) temperature difference, and knowledge of the dissipation at each block and its contact area with the tube.

\section{Experimental Results}

\section{1. $\quad$ Overall performance of the cooling set up with different fluids}

Satisfactory cooling of most of the thermal prototypes of the ATLAS silicon micro strip and pixel detectors was demonstrated and has been reported in detail elsewhere [8]. Tests were made up to the full power dissipation (section 1.). The low boiling pressure $\left(0.350 \mathrm{bar}_{\mathrm{abs}}\right.$ at $\left.\sim-25^{\circ} \mathrm{C}\right)$ and high vapor expansion volume of $\mathrm{C}_{4} \mathrm{~F}_{10}$ return a relatively high volume of vapor at low pressure at the input of the compressor. The temperature gradient $\left(T_{i n}-T_{\text {out }}\right)$ seen on structures tested with $\mathrm{C}_{4} \mathrm{~F}_{10}$ was considerably larger than those seen with the other fluids at the same power, indicating that a larger hydraulic diameter would be needed with $\mathrm{C}_{4} \mathrm{~F}_{10}$ to compensate for the correspondingly higher pressure drop.

\subsection{Sonar tests results}

The sonar analyzer was calibrated with a range of gases before being used with the various refrigerants. The theoretical value of sound velocity, $v_{t}$, for an ideal gas is given by:

$$
v_{t}=\sqrt{\frac{\mathrm{k} R T}{m}},
$$

where $\mathrm{k}$ is the ratio of specific heats, $R$ is the universal gas constant, $T$ the absolute temperature and $m$ the molar mass.

In nitrogen $\{$ helium $\}$ at $21.0^{\circ} \mathrm{C}$ the measured velocities were $349.7\{996.1\} \mathrm{ms}^{-1}$ : around $0.3 \%$ $\{0.2 \%\}$ lower than the ideal gas predictions of $350.6\{998.0\} \mathrm{ms}^{-1}$. The most useful calibration gas was xenon, which combines near ideal behavior with a molar mass (131.3g) closest to those of the heavy refrigerants. Table 2 compares velocity measurements in xenon over a range of temperatures with ideal gas predictions. 
Table 2

Velocity of Sound in Xenon

\begin{tabular}{|c|c|c|c|c|c|}
\hline$T_{\text {tube }}$ & $P_{\text {abs }}$ & sos & Theor. SOS & DIFF=M.-Th. & Rel._Err. \\
\hline [C] & {$\left[\mathrm{MPa}_{\mathrm{abs}}\right]$} & {$\left[\mathrm{ms}^{-1}\right]$} & {$\left[\mathrm{ms}^{-1}\right]$} & {$\left[\mathrm{ms}^{-1}\right]$} & {$[-]$} \\
\hline-5.5 & 0.095 & 166.72 & 167.73 & -1.010 & -0.0061 \\
\hline 0 & 0.107 & 169.22 & 169 & -0.224 & -0.0013 \\
\hline 2.9 & 0.098 & 169.71 & 170.34 & -0.632 & -0.0037 \\
\hline 11.5 & 0.102 & 172.73 & 172.96 & -0.232 & -0.0013 \\
\hline 193 & 0.108 & 175.67 & 175.34 & 0.330 & 0.0019 \\
\hline 20.8 & 0.107 & 176.38 & 175.77 & 0.614 & 0.0035 \\
\hline 27.8 & 0.109 & 178.78 & 177.86 & 0.922 & 0.0052 \\
\hline
\end{tabular}

The first test on a refrigerant was made with $\mathrm{R} 404 \mathrm{~A}^{7}$, for which sound velocities are predicted in the standard NIST REFPROP package [4] according to a modified Benedict-Webb-Rubin equation of state. Our results are summarized in Table 3, and differ by an average relative error of - $0.3 \%$ from the NIST predictions at temperatures above $0^{\circ} \mathrm{C}$, and by $-1.2 \%$ for data below $-10^{\circ} \mathrm{C}$. The observed discrepancy might be explained by a small amount of impurities in the sample $(\sim 1 \%)$ as seen in gas chromatography of the fluid.

Table 3

Velocity of Sound in R404A

\begin{tabular}{|c|c|c|c|c|c|c|c|c|c|c|c|c|}
\hline & \multicolumn{12}{|c|}{ Temperature } \\
\hline & \multicolumn{2}{|c|}{-19.45} & \multicolumn{2}{|c|}{-10} & \multicolumn{2}{|c|}{0} & \multicolumn{2}{|c|}{10} & \multicolumn{2}{|c|}{20} & \multicolumn{2}{|c|}{28} \\
\hline$P$ abs & SOS & STDV & sos & STDV & SOS & STDV & sos & STDV & sos & STDV & SOS & STDV \\
\hline$[\mathrm{MPa}]$ & {$\left[\mathrm{ms}^{-1}\right]$} & {$[-]$} & {$\left[\mathrm{ms}^{-1}\right]$} & {$[-]$} & {$\left[\mathrm{ms}^{-1}\right]$} & {$[-]$} & {$\left[\mathrm{ms}^{-1}\right]$} & {$[-]$} & {$\left[\mathrm{ms}^{-1}\right]$} & {$[-]$} & {$\left[\mathrm{ms}^{-1}\right]$} & {$[-]$} \\
\hline 0.010 & 154.29 & 0.11 & 150.75 & 0.55 & 159.74 & 0.05 & 162.60 & 0.11 & 165.62 & 0.14 & 167.75 & 0.65 \\
\hline 0.020 & 152.21 & 0.30 & 155.41 & 0.20 & 159.56 & 0.15 & 162.57 & 0.14 & 165.60 & 0.50 & 167.60 & 0.36 \\
\hline 0.030 & 152.15 & 0.20 & 155.24 & 0.10 & 159.44 & 0.15 & 162.48 & 0.13 & 164.90 & 0.40 & 167.56 & 0.17 \\
\hline 0.050 & 151.75 & 0.10 & 154.94 & 0.15 & 159.14 & 0.12 & 162.25 & 0.13 & 164.70 & 0.15 & 167.40 & 0.20 \\
\hline 0.070 & 151.26 & 0.16 & 154.72 & 0.18 & 158.35 & 0.10 & 131.70 & 0.13 & 164.38 & 0.14 & 166.92 & 0.19 \\
\hline 0.100 & 150.35 & 0.16 & 153.96 & 0.14 & 157.85 & 0.10 & 161.10 & 0.11 & 163.92 & 0.14 & 166.48 & 0.18 \\
\hline 0.150 & 148.92 & 0.13 & 152.31 & 0.14 & 156.45 & 0.10 & 159.98 & 1.00 & 162.87 & 0.14 & 165.63 & 0.22 \\
\hline 0.200 & 146.92 & 0.11 & 150.64 & 0.13 & 155.07 & 0.10 & 158.69 & 0.10 & 161.75 & 0.14 & 164.62 & 0.19 \\
\hline 0.250 & 144.22 & 0.80 & 149.02 & 0.13 & 153.34 & 0.09 & 157.49 & 0.10 & 160.65 & 0.14 & 163.48 & 0.18 \\
\hline 0.297 & & & 147.69 & 0.10 & 152.09 & 0.13 & 155.80 & 0.09 & 159.37 & 0.25 & 162.38 & 0.14 \\
\hline 0.350 & & & 145.16 & 0.50 & 150.75 & 0.10 & 154.60 & 0.09 & 157.93 & 0.33 & 161.38 & 0.16 \\
\hline 0.400 & & & 143.71 & 0.41 & 148.58 & 0.10 & 153.47 & 0.10 & 156.23 & 0.39 & 160.39 & 0.14 \\
\hline
\end{tabular}

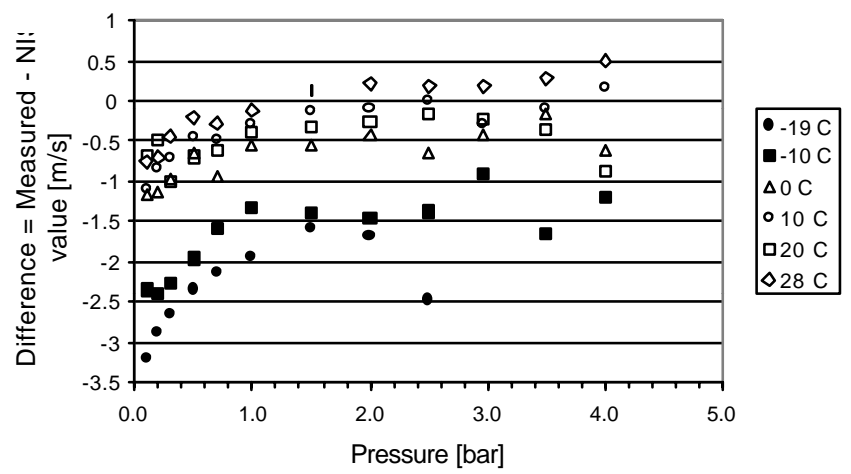

Fig. 3. Differences between measured and predicted values of the velocity of sound in R404A

${ }^{7}$ Mfr.: Prochimac, Neuchatel, Switzerland, 99\% purity 
Similar comparisons were made in the case of $\mathrm{C}_{4} \mathrm{~F}_{10}{ }^{8}$. A provisional data file had been added to the NIST REFPROP package for this fluid. Our measurements for the superheated region are shown in Table 4 and differ by an average relative error of $\sim-0.2 \%$ from the extended NIST predictions at temperatures above $0^{\circ} \mathrm{C}$, and by $\sim-1.2 \%$ for data below $-10^{\circ} \mathrm{C}$.

Table 4

Velocity of Sound in $\mathrm{C}_{4} \mathrm{~F}_{10}$

\begin{tabular}{|c|c|c|c|c|c|c|c|c|c|c|c|c|}
\hline & \multicolumn{12}{|c|}{ Temperature } \\
\hline & \multicolumn{2}{|c|}{-17.9} & \multicolumn{2}{|c|}{-10.0} & \multicolumn{2}{|c|}{-0.1} & \multicolumn{2}{|c|}{10.0} & \multicolumn{2}{|c|}{20.0} & \multicolumn{2}{|c|}{30.0} \\
\hline & sos & STDV & SOS & STDV & sos & STDV & SOS & STDV & sos & STDV & SOS & STDV \\
\hline [MPa] & {$\left[\mathrm{ms}^{-1}\right]$} & {$[-]$} & {$\left[\mathrm{ms}^{-1}\right]$} & {$[-]$} & {$\left[\mathrm{ms}^{-1}\right]$} & {$[-]$} & {$\left[\mathrm{ms}^{-1}\right]$} & {$[-]$} & {$\left[\mathrm{ms}^{-1}\right]$} & {$[-]$} & {$\left[\mathrm{ms}^{-1}\right]$} & {$[-]$} \\
\hline 0.010 & 95.10 & 0.06 & 96.57 & 0.07 & 99.26 & 0.05 & 101.05 & 0.08 & 103.02 & 0.10 & 104.78 & 0.10 \\
\hline 0.020 & 94.56 & 0.04 & 96.22 & 0.04 & 98.71 & 0.05 & 100.64 & 0.07 & 102.70 & 0.08 & 104.57 & 0.08 \\
\hline 0.030 & 93.98 & 0.04 & 95.70 & 0.05 & 98.33 & 0.04 & 100.23 & 0.06 & 102.37 & 0.10 & 104.25 & 0.07 \\
\hline 0.050 & & & 94.78 & 0.04 & 97.39 & 0.04 & 99.38 & 0.06 & 101.71 & 0.12 & 103.35 & 0.12 \\
\hline 0.070 & & & & & 96.39 & 0.07 & 98.40 & 0.05 & 100.86 & 0.05 & 103.06 & 0.05 \\
\hline 0.100 & & & & & 94.79 & 0.10 & 97.04 & 0.05 & 99.66 & 0.05 & 103.05 & 0.08 \\
\hline 0.150 & & & & & & & 95.08 & 0.05 & 97.68 & 0.05 & 99.91 & 0.05 \\
\hline 0.200 & & & & & & & & & 95.63 & 0.05 & 98.41 & 0.07 \\
\hline 0.250 & & & & & & & & & & & 96.50 & 0.05 \\
\hline 0.300 & & & & & & & & & & & 94.89 & 0.05 \\
\hline
\end{tabular}

Tests are continuing with $\mathrm{C}_{3} \mathrm{~F}_{8}{ }^{9}$ and custom mixtures of $\mathrm{C}_{4} \mathrm{~F}_{10}$ and $\mathrm{C}_{3} \mathrm{~F}_{8}$. Comparison data will be included in a forthcoming publication.

\subsection{Thermal Measurement Data - Heat Transfer Coefficients (HTC)}

Typical HTCs for the different fluids measured in the 1.6m "ladder" of Section 2.3 at a dissipation of 8 Watts/block (96 Watts total) are shown in Fig. 4. Values varied in the range

$(2-5) \cdot 10^{3} \mathrm{Wm}^{-2} \mathrm{~K}^{-1}$ depending on the fluid. The highest HTCs were seen in the case of $\mathrm{C}_{3} \mathrm{~F}_{8}$, and the lowest with $50 / 50 \mathrm{C}_{4} \mathrm{~F}_{10} / \mathrm{C}_{3} \mathrm{~F}_{8}$.

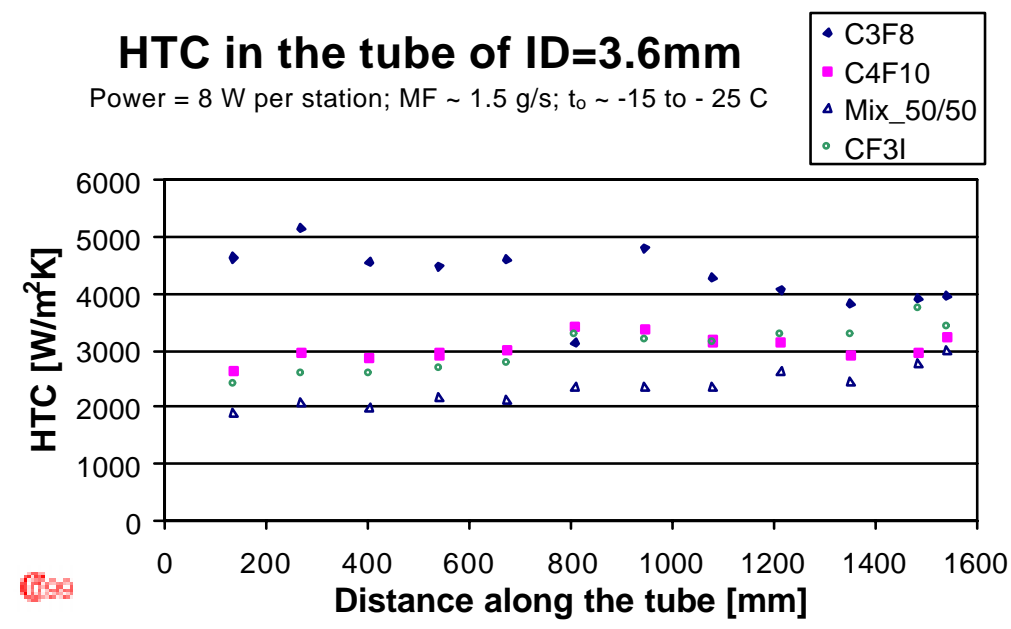

Fig. 4. Heat Transfer Coefficients in a 3.6mm ID tube: $\mathrm{C}_{4} \mathrm{~F}_{10}, \mathrm{CF}_{3} \mathrm{I}, \mathrm{C}_{3} \mathrm{~F}_{8}$

and $50 \% \mathrm{C}_{4} \mathrm{~F}_{10} / 50 \% \mathrm{C}_{3} \mathrm{~F}_{8}$ mixture at similar power and flow rate.

\footnotetext{
${ }^{8}$ Mfr.: 3-M Corp. Specialty Chemicals Division, St. Paul, MN, USA PFG 5040, grade $>99 \%$ purity

${ }^{9}$ Mfr: 3-M Corp. Specialty Chemicals Division, St. Paul, MN, USA PFG 5030, grade >99\% purity
} 
Heat transfer coefficients were also measured as a function of $\mathrm{C}_{4} \mathrm{~F}_{10} / \mathrm{C}_{3} \mathrm{~F}_{8}$ relative concentration (Fig. 5), and were found to increase as the mixture became richer in one or other of the components. Similar effects in mixtures have been reported elsewhere [6].

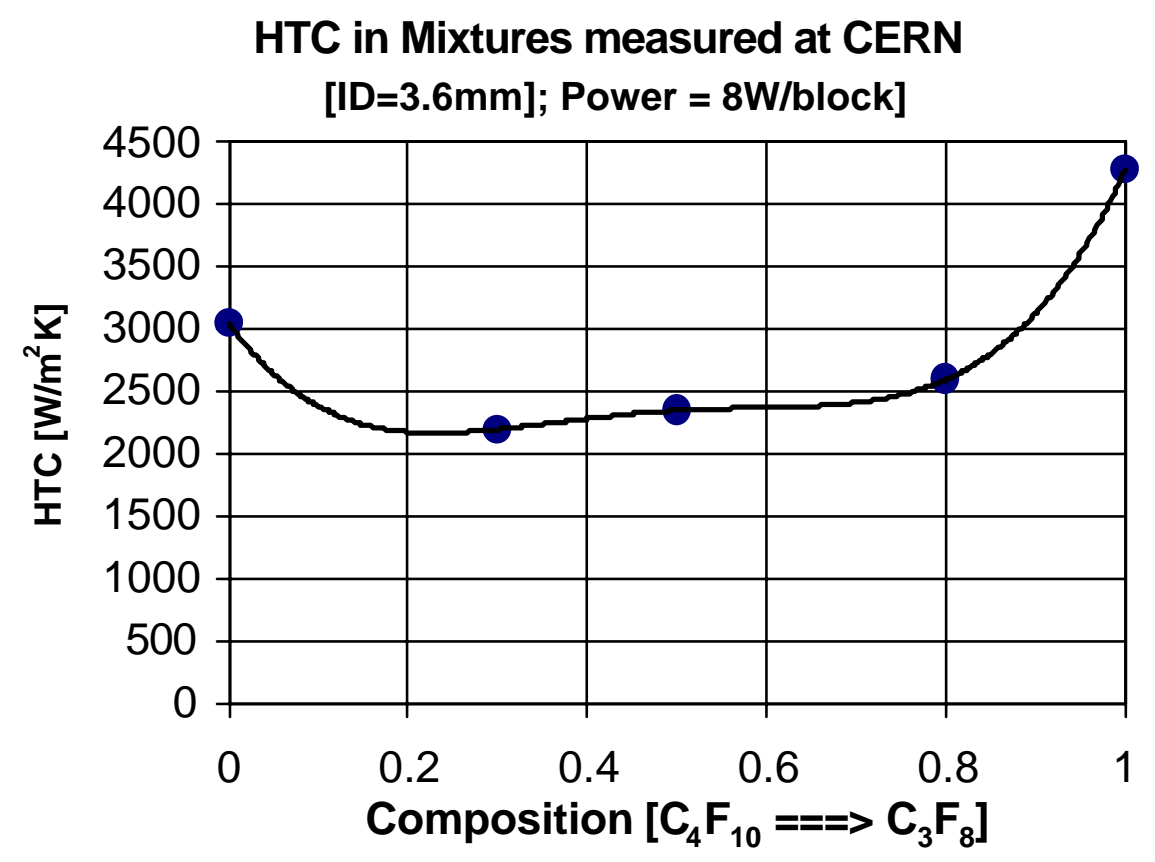

Fig. 5. Measured variation of the Heat Transfer Coefficient in a $3.6 \mathrm{~mm}$ ID tube with changing $\mathrm{C}_{4} \mathrm{~F}_{10} / \mathrm{C}_{3} \mathrm{~F}_{8}$ mixture composition.

\subsection{Refrigerant Irradiation Studies}

\subsubsection{Neutron Irradiation}

Small $\left(<10 \mathrm{~cm}^{3}\right)$, static liquid samples of perfluoro-n-hexane $\left(\mathrm{C}_{6} \mathrm{~F}_{14}\right)^{10}, \mathrm{CF}_{3} \mathrm{I}^{11}$, solid Teflon and iodine $\left(\mathrm{I}_{2}\right)$ were irradiated up to $3.10^{13}$ fast neutrons. $\mathrm{cm}^{-2}$ to simulate the expected environment at LHC. Studies showed the main longest-lived radioisotopes to be ${ }^{18} \mathrm{~F}$ (106 min: $511 \mathrm{KeV} \gamma$ emitter) and ${ }^{128} \mathrm{I}$ ( $25 \mathrm{~min}: 433 \mathrm{KeV} \gamma$ emitter). From neutron capture cross section data, the expected activity levels for these radionuclides are in the range $10^{4}-10^{5}$ Bq.g ${ }^{-1}$ during circulation (for an instantaneous rate $\sim 10^{6}$ neutrons. $\mathrm{cm}^{-2} \mathrm{~s}^{-1}$ ), which is believed to be acceptable in a closed circuit system. However, the overall measured level of $\mathrm{I}_{2}$ activation was considered too high to allow the use of $\mathrm{CF}_{3} \mathrm{I}$ in our application.

\subsubsection{Radiation-Induced Chemical Modifications}

Small $\left(<10 \mathrm{~cm}^{3}\right)$, static liquid samples of $\mathrm{C}_{6} \mathrm{~F}_{14}$ and $\mathrm{CF}_{3} \mathrm{I}$ were exposed to ${ }^{60} \mathrm{C}$ gamma irradiation. After an absorbed dose of $3 \mathrm{MRad}$, about $1 \%$ by weight of $\mathrm{C}_{6} \mathrm{~F}_{14}$ liquid had been

\footnotetext{
${ }^{10}$ Mfr.: 3-M Corp. Specialty Chemicals Division, St. Paul, MN, USA PFG 5060 grade >99\%purity

${ }^{11}$ Mfr.: Ajay North America Inc. Powder Springs, GA, 30127-0127, USA
} 
chemically modified: there was chemical evidence of the production of reactive $\mathrm{HF}$, due to impurities containing C-H groups. Scanning electron microscopy and Auger electron spectroscopy were used to characterize the morphologies and elemental compositions of C-, F- and O-containing polymeric deposits formed on stainless steel and aluminum samples immersed in liquid during irradiation. After $6 \mathrm{MRad}$, surfaces were almost uniformly covered with a polymeric layer of $\sim 0.4 \mu \mathrm{m}$. Degradation and plate-out were greater in a sample of $\mathrm{C}_{6} \mathrm{~F}_{14}$ to which $3 \%$ (vol.) n-heptane had been added to act as a $\mathrm{H}$-source and simulate the hydrogen containing impurities.

Since saturated fluorocarbons $\left(\mathrm{C}_{\mathrm{n}} \mathrm{F}_{(2 \mathrm{n}+2)}\right)$, are synthesized from alkane precursors, batch testing for residual $\mathrm{H}$ contamination (using the characteristic Fourier Transform Infra-Red signature of $\mathrm{C}-\mathrm{H}$ bonds) is advisable. Techniques for the catalytic removal of $\mathrm{C}_{n} \mathrm{~F}_{(2 n+2-x)} \mathrm{H}_{\mathrm{x}}$ contamination have been developed at CERN [11], and could be used in the present application.

After irradiation to $2 \mathrm{MRad}$, liquid $\mathrm{CF}_{3} \mathrm{I}$ had become opaque and breakdown of $\mathrm{CF}_{3} \mathrm{I}$ into $\mathrm{I}_{2}$ and $\mathrm{HI}$ was seen. This was not a complete surprise, since $\mathrm{CF}_{3} \mathrm{I}$ is a refrigerant with a short ( $\left.24 \mathrm{hr}\right)$ atmospheric half-life. Oily residues (pre-polymers) were observed after the evaporation of the irradiated $\mathrm{CF}_{3} \mathrm{I}$, and thick deposits, including crystalline $\mathrm{I}_{2}$ were observed on aluminum and stainless steel immersion samples. Although it was possible to clean the $\mathrm{CF}_{3} \mathrm{I}$ to remove $\mathrm{I}_{2}$ and re-establish the transparency, $\mathrm{CF}_{3} \mathrm{I}$ was finally abandoned as a coolant owing to its chemical agressivity, even in the un-irradiated state, to elastomer seal materials and also to its high radioactivation in neutron fields.

\section{Conclusions}

Evaporative cooling has been demonstrated at the full power dissipation of the ATLAS SCT and pixel detectors. Studies with engineering prototypes and measurements of heat transfer coefficient indicate that $\mathrm{C}_{3} \mathrm{~F}_{8}$ is presently the best candidate refrigerant. The low boiling pressure of $\mathrm{C}_{4} \mathrm{~F}_{10}$ $\left(\sim 350\right.$ mbar $_{\text {abs }}$ at $\left.\sim-25^{\circ} \mathrm{C}\right)$ allows a small pressure head to drive vapor back to the compressor input. Of the fluids with "optimum" thermodynamics (i.e. a saturated vapor pressure $\sim 1$ bar $_{\text {abs }}$ at $\left.-25^{\circ} \mathrm{C}\right), \mathrm{C}_{3} \mathrm{~F}_{8} / \mathrm{C}_{4} \mathrm{~F}_{10}$ custom mixtures are less favored due to lower heat transfer coefficient.

Sound velocity measurements made in light gases and xenon compared well with ideal gas predictions. Comparisons with calculations from the NIST package in the low pressure superheated region for $\mathrm{R} 404 \mathrm{~A}$ and $\mathrm{C}_{4} \mathrm{~F}_{10}$ also showed good agreement, to better than $0.3 \%$ above $0^{\circ} \mathrm{C}$ region, and to $\sim-1.3 \%$ for data below $-10^{\circ} \mathrm{C}$.

Irradiation results suggest that perfluorocarbons (fully fluorinated saturated alcanaes) should be useable in our application. However, $\mathrm{CF}_{3} \mathrm{I}$ was rejected due to its poor chemical stability under ionizing radiation, and radioactivation concerns.

\section{List of symbols}

$v_{t} \quad$ theoretical (ideal gas) sound velocity $\left(\mathrm{ms}^{-1}\right)$

$\mathrm{P}$ pressure (MPa, bar)

$R \quad$ universal gas constant $\left(8.314 \mathrm{~J} \mathrm{~mol}^{-1} \mathrm{~K}^{-1}\right)$

ID inner diameter ( $\mathrm{mm})$ 


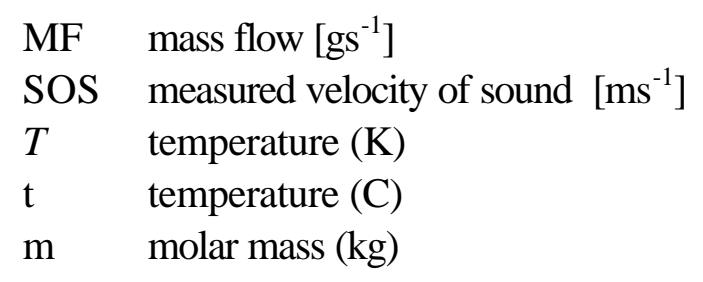

$\mathrm{Bq}$ radioactive decays per second

\section{Acknowledgments}

The authors thank S. Berry, P. Bonneau, M. Bosteels and P. Ferraudet (CERN) for their help in fabricating the evaporative fluorocarbon recirculators, and J. Thadome (Univ. Wuppertal, Germany) for his help in fabricating the sonar gas analyzer. The research was partly supported by grant No.: CEZ:J04/98:212200008.

\section{References:}

[1] ATLAS Pixel Detector Technical Design Report CERN/LHCC/98-13, 31 May 1998

[2] ATLAS Inner Detector Technical Design Report CERN/LHCC/97-16/17, April 1997

[3] G. Hallewell, G. Lenzen, J. Thadome, V. Vacek et al: Progress in Fluorocarbon Evaporative Cooling, ATLAS Pixel Mechanics Meeting, and also ATLAS Review of Cooling System, CERN September 1997

[4] NIST Thermodynamic and Transport Properties of Refrigerants and Refrigerant Mixtures - REFPROP PACKAGE [with extensions], Version 6.01, NIST Gaithersburg, 1998

[5] M.Lísal, V.Vacek: Direct evaluation of vapour-liquid equilibria of mixtures by molecular dynamics using Gibbs-Duhem integration, Molecular Simulation, 18: (1996), 75

[6] M. Lísal, R. Budinský, V. Vacek:"Vapour-liquid Equilibria for Dipolar Two-Centre LennardJones Fluids by Gibbs-Duhem Integration” Fluid Phase Equilibria, 135 (1997), 193

[7] G. Hallewell et al: "A sonar based technique for the ratiometric determination of binary gas mixtures", Nucl.Instr. \& Meth. A264, (1988), 219.

[8] E. Anderssen, G. Hallewell, V. Vacek, et al: "Fluorocarbon Evaporative Cooling Developments for the ATLAS Pixel and Semiconductor Tracking Detectors", Proc. Fifth Workshop on Electronics for LHC Experiments, Snowmass Co. USA, (September, 1999); also at CERN 99-09 CERN/LHCC99-33, October 1999.

[9] T. Inoue, N. Kawae, M. Monde: Characteristics of Heat Transfer Coefficient During Nucleate Pool Boiling of Binary Mixtures", Heat \& Mass Transfer 33 (1998), 337

[10] S. Ilie, G. Lenzen: 'Perfluorocarbon Liquid: Specific Chemical Aspects for use within the DELPHI Ring Imaging Cerenkov Detector", DELPHI 93-33 RICH54, CERN, 1993. 